\title{
How does foreign accent affect template matching mechanisms? ERP evidence from Polish
}

\author{
Hanna Kędzierska \\ University of Wroctaw, Poland
}

\begin{abstract}
Sentential context is believed to have particularly robust effects on the processing of foreign-accented speech (LevAri 2015). However, recent neurolinguistic studies investigating the relation between non-native speech and semantic predictability suggest that anticipation mechanisms are, in fact, hampered during the processing of foreign accents (Romero-Rivas et al. 2016). The current study is an attempt to shed more light on this issue and establish whether the mechanisms responsible for categorical template matching remain active during the processing of non-native speech. The study investigated neural reactions towards high cloze probability template endings (i.e., the endings of fixed phrases selected in a pre-test) and their unexpected counterparts. 120 Polish sentences were recorded by a native Polish speaker and a non-native (L1 Ukrainian) speaker of Polish in order to investigate the reactions towards an easily recognizable foreign accent. The brain activity of 28 monolinguals (L1 Polish) was recorded during the EEG sessions. In native-accented speech, violations of high cloze probability items resulted in a broadly distributed negativity followed by a P600 effect. No comparable effects were observed in the case of foreign-accented speech. These results are compatible with previous findings (Hanulíková et al. 2012; Romero-Rivas et al. 2016) as they confirm that linguistic anticipatory and reanalysis processes are hampered in the case of non-native speech.
\end{abstract}

Keywords: ERPs, comprehension, prediction, bilingualism, accent

\section{Introduction}

With an increase in global migration and the sustaining status of English as a lingua franca, biand multilingual communication has become an inherent property of European societies. Crucially, bi- or multilingual speakers usually lack native competences in their non-native language in terms of grammar, lexis, and pronunciation (Flege 1995; Flege et al. 1995; Grosjean 2010). One of the most characteristic properties associated with non-native speakers is their foreign accent, which can influence non-native speech perception and comprehension. Due to diminished intelligibility, non-native speech is believed to be harder to process when compared with native speech, which is reflected in extra processing time (as indicated by many studies based on transcriptions, lexical decisions, or semantic judgements; e.g., Adank et al. 2009; 
Bradlow and Bent 2008; Cristia et al. 2012; Floccia et al. 2006; Lindemann 2002). The adverse listening conditions are believed to enhance already existing prejudices and stereotypes (LevAri and Keysar 2010; Oppenheimer 2008). For instance, it has been demonstrated that children show biases to befriend native-accented over foreign-accented individuals (Souza et al. 2013). The processing difficulties are also assumed to affect the way in which stimuli are consciously perceived and judged. Studies indicate that non-native speakers are perceived as less credible when compared with native speakers (Lev-Ari and Keysar 2010). Foreign-accented speakers are also commonly assessed as less intelligent, less responsible and less competent than native speakers (Radomski and Szpyra-Kozłowska 2014; Said 2006).

\subsection{ERP investigations into foreign-accented speech}

Only a few event-related brain potential (ERP) studies investigating the processing of foreignaccented speech have been carried out so far (Caffarra and Martin 2018; Goslin et al. 2012; Grey and van Hell 2017; Hanulíková et al. 2012; Romero-Rivas et al. 2015; Romero-Rivas et al. 2016). Due to its high temporal resolution and non-invasiveness, the ERP method provides a highly powerful tool to measure and average the brain activity by electrodes placed on the subject's scalp (for a more detailed review of the method see, e.g., Harley 2013; Kaan 2007; Otten and Rugg 2005; Woodman 2010). In psycho- and neurolinguistic studies, language processing is typically investigated in terms of the so-called ERP components, i.e., the waveforms elicited as a response towards a specific manipulation. The three crucial language-related ERP components associated with consecutive language processing stages are: (E)LAN, that is (early) left anterior negativity (associated with phrase structure or morphosyntactic violations), N400 (elicited as a response towards semantic anomalies), and P600 (associated with syntactic reanalysis and revision) (Federmeier and Kutas 1999; Friederici and Weissenborn 2007; Gouvea et al. 2009; Kutas and Hillyard 1980, among many others).

In terms of ERP components, two notable differences have been observed in the comprehension of native as opposed to non-native speech. First, no P600 response emerges during the processing of non-native speech, which suggests that the reanalysis mechanisms are absent, or at least hampered, while listening to foreign-accented speakers ${ }^{1}$ (Hanulíková et al. 2012; Romero-Rivas et al. 2015). Also, non-native speech can be associated with shallower semantic processing, perhaps due to higher cognitive demands in terms of lexical access (Goslin et al. 2012; Hanulíková et al. 2012).

Quite crucially, the status of the listeners (and particularly their previous exposure towards a given type of accent) seems to affect the processing of a foreign accent. Grey and van Hell (2017) presented their subjects with sentences containing pronoun mismatches (Thomas was planning to attend the meeting but he/* she missed the bus to school; Grey and van Hell 2017: 96), uttered both by a native- and a non-native (L1 Chinese) speakers of English. They observed a discrepancy in the foreign-accented speech condition with respect to those subjects who have correctly identified the place of origin (i.e., Asia) of the non-native speaker, and those who were

1 The P600 component might be observed in the case of less typical errors, though, which would suggest that the reanalysis mechanisms are not hampered in the case of more common errors (see Caffarra and Martin 2018). 
not able to identify it. The subset of participants who recognized the foreign accent presented in the study showed a neural response towards grammatical anomalies in both native and nonnative accent conditions, while subjects who did not identify the accent of the non-native speaker did not show any ERP effect (Grey and van Hell 2017: 106). Hence, it seems vital to carefully control for the type of accent which is examined but also for the kind of listeners who are researched (i.e., their possible exposure towards a given accent, and their own status as mono vs. multilingual speakers).

Foreign-accented speech can intuitively be associated with increased reliance on contextual cues. It can be viewed as the listener's strategy to process language in adverse listening conditions (Lev-Ari 2015). In terms of the ERP components, the mechanisms of anticipation are usually reflected in the amplitude of the N400 component which can be strongly influenced by predictive language processing. Federmeier and Kutas (1999) used the paradigm of expected (1a) as opposed to unexpected (lb-c) words embedded in short stories of the following kind:

(1) The tourist in Holland stared in awe at the rows and rows of colour. She wished she lived in a place where they grew

a. tulips

b. roses

c. pines.

Federmeier and Kutas (1999: 473)

The condition containing highly expected words (1a) elicited a smaller N400 amplitude when compared with the other two endings ( $1 \mathrm{~b}-\mathrm{c}$ ). Quite interestingly, the words belonging to the same semantic category as the best completion (1b) elicited a smaller N400 amplitude when compared with the words belonging to a different semantic category (1c) (Federmeier and Kutas 1999: 484). This finding would suggest that semantic or perceptual features of the upcoming word are pre-activated already before the word is encountered.

Romero-Rivas et al. (2016) used the same cloze probability paradigm as Federmeier and Kutas (1999) in order to check whether similar effects will be obtained in the context of foreignaccented speech. In native speech, the elicited N400 effect remained gradual in nature (i.e., it was the strongest for the best completion, weaker for related words and the weakest for unrelated words). In the case of non-native speech, though, they observed the decreased N400 amplitude for best completions but no differences emerged between related and unrelated conditions. That would suggest that when exposed to foreign-accented speech, listeners do make predictions about the most probable completion of a sentence but the related words do not benefit from anticipatory processes. The increased reliance on sentential context would then direct the comprehender solely at the most probable completion, narrowing down the list of potential lexical candidates matching the context. The aim of the current study was to shed more light on this issue by determining whether the mechanisms responsible for categorical template matching remain active during the processing of a common and easily recognizable foreign accent. 


\subsection{Present study}

The main objective of the experiment was to investigate neural responses towards templates, which could be defined as multiword strings stored in semantic memory. And more specifically, the study investigated brain reactions towards high cloze probability words embedded in a supportive sentential context (2a) and their unexpected counterparts (2b).

\section{(2) a. Podczas kłótni Paweł był wściekły, więc zadał cios poniżej pasa i powiedział całą prawdę. 'During the argument Paul was furious so he hit below the belt and told the truth.' \\ b Podczas kłótni Paweł był wściekły, więc zadał cios poniżej brzucha i powiedział całą prawdę. 'During the argument Paul was furious so he hit below the stomach and told the truth.'}

The processing of templates, also known as deterministic processing, involves the comprehension of highly probable, unique endings, such as the endings of fixed phrases of conventionalized figurative meaning (cry over spilt milk; Vespignani et al. 2010) but also, for instance, antonym pairs (The opposite of white is black; see Roehm et al. 2007). The cloze probability of the target word (which is usually the final word) is often close to 1 . In order to determine this, the so-called cloze probability tasks have to be conducted, i.e., the kind of open cloze tasks in which the subjects are asked to complete a given sentence or phrase. This would mean that nearly $100 \%$ of the cloze task participants would have to complete the template with a given target word. In ERP studies, the detection of the unique, highly expected ending is usually associated with the reduced amplitude of the N400 component (Federmeier and Kutas 1999) but also with the so-called P3b component, which is often considered a marker of expectation verification mechanisms (Roehm et al. 2007; Vespignani et al. 2010). P3b is a subcomponent of the P300 and could be defined as posterior positivity elicited around 300 milliseconds after the onset of the highly predictable word or phrase, matching the stored template (Polich 2012). If the list of potential candidates matching the sentential context is indeed narrowed during the comprehension of foreign-accented speech, the template matching mechanisms should also be active (or even more pronounced) in the case of foreign-accented speech. On the other hand, assuming that due to the increased reliance on contextual cues, one selects a larger set of candidates while listening to non-native speakers, the template matching mechanisms should also be hampered. This should be reflected in ERP components elicited as a response to sentences presented in (2a-b) in native as opposed to foreign-accented speech.

Importantly, the previously mentioned studies, and especially those which investigated semantic processing in foreign-accented speech, focused on the processing of accents which were either uncommon and difficult to recognize, such as Chinese accent in English (Grey and van Hell 2017), or used many different accents, such as Italian and French accents in Spanish (Romero-Rivas et al. 2016), or Italian and Polish accents in English (Goslin et al. 2012). Hence, one of the questions which the current study aimed to answer was whether the prediction verification mechanisms will be active during the processing of an easily recognizable and common type of accent. For this reason, we decided to investigate the eastern (and more specifically, Ukrainian) accent in the Polish language. Ukrainian people constitute one of the 
biggest minorities in Poland, with the number of Ukrainians residing in Poland estimated at around 1 million (Daniel 2019: 147).

\section{Methodology}

\subsection{Participants}

Twenty-eight monolingual native speakers of Polish volunteered to participate in the study. They all had normal or corrected-to-normal vision and reported no neurological disorders or hearing disabilities. Three participants were excluded from the analysis due to excessive artefacts in the raw EEG data (1) or technical problems during the recording sessions (2). Hence, data from 25 listeners (mean age: 21.96, age range: 19-29, 7 males) were included in the ERP analysis. All the participants were right-handed as assessed by the Edinburgh Handedness Inventory (Oldfield 1971). None of them reported daily interactions with foreign-accented speakers or living abroad for longer than a few weeks. The participants were all college students or college graduates. As previous studies showed that mono/bilingual status of the listeners might affect the neural responses towards non-native speech (Grey and van Hell 2017), there were no balanced bilinguals recruited to take part in the study.

\subsection{Materials and pre-tests}

The experimental stimuli consisted of 120 sentences, which contained templates. Each sentence appeared in two versions: a version containing an expected template ending (Condition 1) and a version containing an unexpected template ending (Condition 2). All the sentences were recorded by two speakers: a male native speaker of Polish (age $=26)$ and male non-native speaker of Polish (L1 Ukrainian, age $=39$ ). Hence, the number of target items amounted to 480 sentences, which were later evenly distributed across four experimental lists with the aid of the Latin square design. In addition, 240 filler sentences containing various kinds of grammatical and semantic mistakes were recorded by each speaker and incorporated into the experimental material (see Table 1 for a more detailed presentation of the experimental stimuli). The Ukrainian speaker spoke Polish fluently but with a clear foreign accent as assessed by an independent group of 20 subjects in a pre-test. On average, the strength of the accent was assessed as 3.9 on a scale from 1 (no accent) to 5 (very strong accent). Crucially, all the subjects participating in the pre-test were able to identify the speaker's region of origin as Ukraine or Russia, which indicates that the accent was easy to recognize.

Table 1: Selected sentences used in the study with English translations

Sentences containing templates in Condition 1 (C1) and Condition 2 (C2)

Do niedawna Paweł był bardzo zakochany w narzeczonej, więc miał klapki na (C1) oczach / (C2) nogach i ignorował jej wady. 
Until recently, Paul was so madly in love with his fiancée that he had blinkers on his (C1) eyes / (C2) feet and ignored her faults.

Po egzaminie Kasia była z siebie zadowolona, więc czuła się lekka jak (C1) piórko / (C2) okruch i odetchnęła $\mathrm{z}$ ulgą.

After the exam, Kate was really satisfied with herself so she felt as light as a (C1) feather / (C2) crumb and breathed a sigh of relief.

Przed momentem Tomek umierał z nudów, więc przeczytał baśń o kocie w (C1) butach / (C2) mieście i natychmiast się rozchmurzył.

A moment ago, Tom nearly died of boredom, so he read a fairy tale about the Puss in (C1) Boots / (C2) Town and he cheered up.

\section{Fillers}

Po podróży Anna była spragniona, więc napiła się soku/*kabla i usiadła wygodnie na sofie. After the journey Anne was thirsty so she drank some juice/*cable and sat comfortably on the sofa.

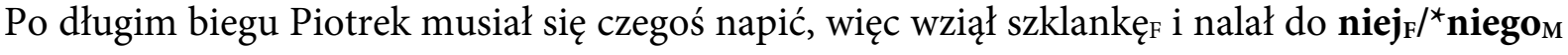
wody mineralnej.

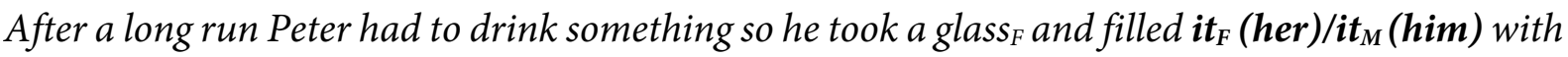
water.

The fixed phrases used in the study have been selected on the basis of the responses obtained in a cloze probability pre-test. 35 native speakers of Polish (none of whom participated in the main study) were asked to complete the preselected templates containing fixed phrases of various kinds, such as idioms, similes, antonym pairs, strong collocations and titles (see Table 1) with the first word which would come to their mind. Only 120 phrases for which the cloze probability exceeded the .9 threshold were selected to be used in the ERP study. Mean cloze probability for items in the expected ending condition (Condition 1) amounted to .92, while the cloze probability of items used in the unexpected ending condition (Condition 2) equalled 0 (i.e., no continuations used in this condition were ever provided by the respondents). The target items were also matched in terms of frequency, which was obtained from the Conversational Spoken Corpus of Polish (PELCRA; Pęzik 2012) (mean frequency in Condition 1: 277.1; mean frequency in Condition 2: 273.9; $\mathrm{W}=7306, \mathrm{p}=0.8445$ ). All target words were 2-syllable long. The word pairs used in the same sentence in Condition 1 and Condition 2 always started with a different phoneme. The mean duration of the critical words was $360 \mathrm{msec}(\mathrm{SD}=163 \mathrm{msec})$ in the native speech and $459 \mathrm{msec}(\mathrm{SD}=189 \mathrm{msec})$ in the nonnative speech $(\mathrm{t}(1408.65)=-10.68, \mathrm{p}<.0001)$. The mean duration of the whole sentence was $5844 \mathrm{msec}(\mathrm{SD}=776 \mathrm{msec})$ in the native speech and $7486 \mathrm{msec}(\mathrm{SD}=1136 \mathrm{msec})$ in the nonnative speech $(\mathrm{t}(1438)=-32.02, \mathrm{p}<.0001) .{ }^{2}$ The loudness of all sentences was adjusted to the same level.

\footnotetext{
2 The durations of the stimuli were significantly longer in foreign-accented as opposed to native speech. However, such duration differences are viewed as an inherent property of non-native speech (Grey and van Hell 2017; Hanulíková et al. 2012 and Romero-Rivas et al. 2015).
} 
In order to make sure that the errors are easily detectable in both native and non-native speech, an error detection task was conducted. An independent group of 20 university students from the University of Wroclaw ( 17 females, mean age $=23.3$, none of them participated in the EEG experiment) were exposed to a randomly selected sample $(\mathrm{N}=60)$ of sentences, evenly distributed across the experimental conditions (i.e., 15 correct and 15 incorrect sentences uttered by the native speaker, and 15 correct and 15 incorrect sentences uttered by the nonnative speaker). The task of the subjects was to press a key as soon as they identify the mistake. Mean error detection accuracy in the case of native speech was $88.15 \%$, while mean error detection accuracy in the case of non-native speech was $85.55 \%$. No statistically significant difference was observed between the two conditions $(\mathrm{t}(30.78)=0.88481$, p-value $=0.3831$ ), which confirms that the experimental stimuli were equally comprehensible, and that the errors were easy to detect in both native and in non-native speech.

\subsection{Procedure}

A single ERP session lasted approximately $2.5 \mathrm{~h}$, including the placement of the EEG cap. The participants were tested individually in a sound-attenuated room. At the beginning of each session, the participants provided informed consent and filled in a short survey concerning hand dominance and language background. The main experiment was preceded by a training session (10 fully correct sentences uttered by a female native speaker of Polish) and was divided into 6 experimental blocks. After each block, the subjects had an opportunity to take a break. The sentences were presented binaurally at a constant sound level via loudspeakers. Each trial started with a fixation cross which remained on the screen until the offset of the sentence. 120 sentences (one third of the whole experimental stimuli) were followed by comprehension yesno questions. The sentences were presented in a pseudorandomized order so that two critical sentences were always separated by at least one filler item.

\subsection{EEG acquisition and analysis}

The EEG activity was measured with the use of $26 \mathrm{Ag} / \mathrm{AgCl}$-electrodes placed at the elastic cap at Fz, FCz, Cz, CPz, Pz, POz, F3, F7, F4, F8, FC1, FC2, FC5, FC6, C3, C4, CP5, CP6, T7, T8, P3, $\mathrm{P} 4, \mathrm{P} 7, \mathrm{P} 8, \mathrm{O} 1, \mathrm{O} 2$. The ground was positioned at AFz. In addition, two electrodes were placed above (VEOG1) and below (VEOG2) the left eye, two electrodes were placed at the outer canthus of each eye (HEOG1 and HEOG2), and two electrodes were placed at the right and left mastoid bone (A1 and A2). The signal was referenced online to the left mastoid electrode (A1). Offline, the recording reference was replaced by Common Average Reference formed by all EEG channels, and the data was filtered with a $0.016 \mathrm{~Hz}(12 \mathrm{~dB})-40 \mathrm{~Hz}(24 \mathrm{~dB})$ band-pass filter. Impedances were kept below $5 \mathrm{k} \Omega$. The EEG data was processed with the aid of the Brain Vision Analyzer 2 software (Brain Products, Gilching). An ICA blink correction was performed, followed by a semi-automatic Raw Data Inspection (maximal allowed voltage step: $50 \mu \mathrm{V} / \mathrm{ms}$, maximal allowed difference of values in intervals: $200 \mu \mathrm{V} / \mathrm{ms}$, minimal allowed amplitude: $100 \mu \mathrm{V}$, minimal allowed amplitude: $-100 \mu \mathrm{V}$ ). Only data free of ocular and muscle artefacts 
were included in the analysis. On average, $9.63 \%$ of trials were excluded. Mean rejection rates per condition were: $10 \%$ ( $\mathrm{SD}=9.77 \%$ ) for Condition 1 and $9.73 \%$ (SD $=12.28 \%$ ) for Condition 2 in native speech, and 10.4\% ( $\mathrm{SD}=12.28 \%$ ) for Condition 1 and $8.8 \%$ (SD = 9.94\%) for Condition 2 in non-native speech. For each target word an epoch of $1200 \mathrm{~ms}$ was obtained: from $200 \mathrm{~ms}$ before the onset of the target word to $1000 \mathrm{~ms}$ after the onset of the target word. A baseline correction was performed to a $200 \mathrm{~ms}$ pre-stimulus onset.

Statistical analyses were performed separately for native and non-native speech on two main time windows: $200-500$ and 500-800, defined on the basis of visual data inspection and previous research (e.g., Grey and van Hell 2017; Romero-Rivas et al. 2016). Also, we defined three regions of interest: ANTERIOR (Fz, F3, F7, F4, F8, FCz, FC1, FC2, FC5, FC6), CENTRAL (Cz, C3, C4, CPz, CP5, CP6, T7, T8), and POSTERIOR (Pz, P3, P4, P7, P8, POz, O1 and O2) on the basis of previous studies (see Grey and van Hell 2017; Hanulíková et al. 2012; RomeroRivas et al. 2015 for similar approaches).

We calculated a repeated measures ANOVA of the mean voltages per condition for the chosen time windows. The analyses included the factors TOPOGRAPHY (anterior, central, posterior) and CONDITION (expected ending, unexpected ending).

\section{Results}

\subsection{Sentence comprehension}

When it comes to the behavioural results of the study, the results were very high in terms of accuracy $(\mathrm{M}=87.97 \%, \mathrm{SD}=4.72 \%)$, also when the sentences were divided into the ones uttered by the native-accented speaker $(\mathrm{M}=88.00 \%, \mathrm{SD}=6.03 \%)$ and the foreign-accented speaker $(\mathrm{M}=87.93 \%, \mathrm{SD}=5.21 \%)$. The comprehenders performed only slightly better during the comprehension of native as opposed to foreign-accented speech, with the difference being statistically not significant $(\mathrm{t}(31.84)=-0.12531$, $\mathrm{p}$-value $=0.4504)$.

\subsection{ERP results}

Visual data inspection suggested that unexpected template endings (Condition 2) elicited a globally distributed N400-like effect in the early (i.e., 200-500 ms) time window in the case of native-speech. The effect was less pronounced and visible only in anterior regions in the case of non-native speech (see Figure 2). In native speech, the negativity was followed by a positivity observed in the 500-800 ms time window. The scalp distribution of the effect was maximal in the posterior regions, which is compatible with the distribution of the P600 component (Gouvea et al. 2009). Voltage difference maps and examples of grand mean ERP waveforms are presented in Figure 1 and Figure 2 respectively. Grand average means were extracted at $200 \mathrm{~ms}$ before until $1000 \mathrm{~ms}$ after the onset of the critical word. For the purpose of visual presentation only, the averages were filtered with a $10 \mathrm{~Hz}$ low-pass filter. 
NATIVE-ACCENTED SPEECH
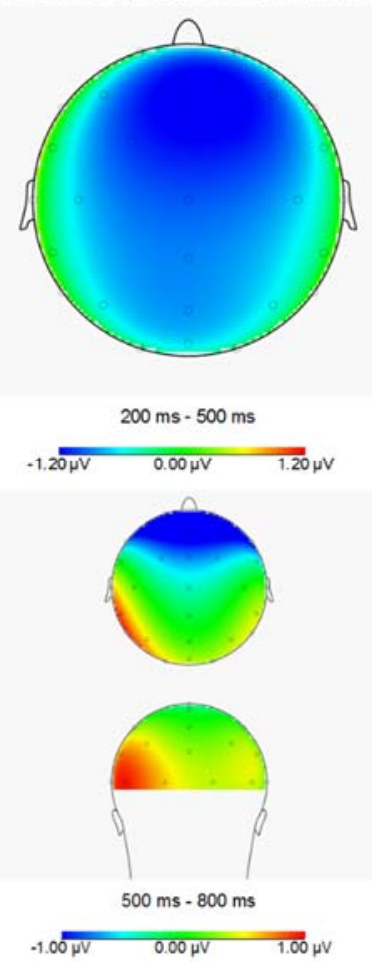

FOREIGN-ACCENTED SPEECH

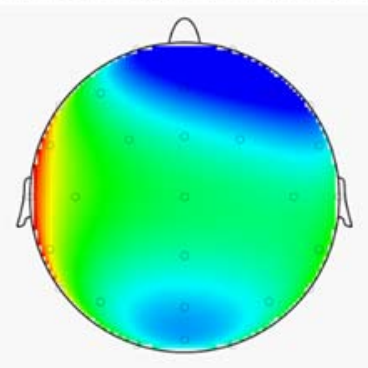

$200 \mathrm{~ms}-500 \mathrm{~ms}$

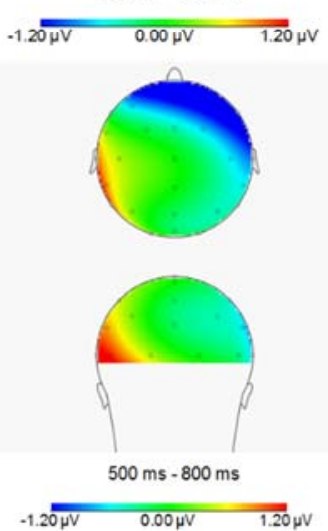

Figure 1: Topographic distribution of voltage differences between conditions (UNEXPECTED ENDING minus EXPECTED ENDING) in native (left) and foreign-accented speech (right) in 200-500 and 500-800 ms time windows.
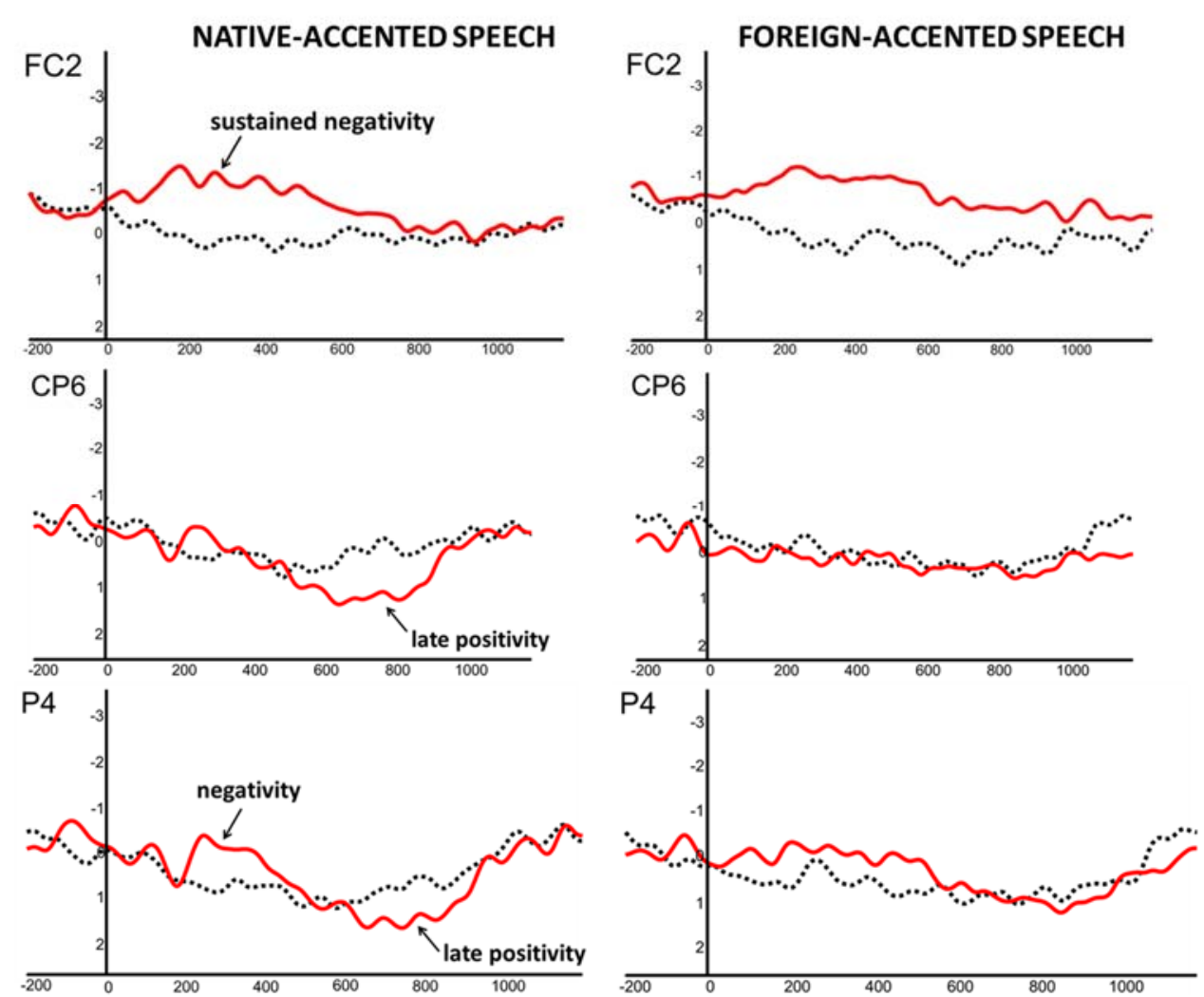

Figure 2: Grand average ERPs from selected electrodes (FC2, CP6, P4) for the critical words of the expected (black line) versus unexpected (red line) template endings in native (left) as opposed to foreign-accented speech (right). 
In native-accented speech, the ANOVA revealed a statistically-significant main effect of CONDITION $(F=5.609, \mathrm{p}=0.026)$ in the $200-500 \mathrm{~ms}$ time window. No significant main effect of TOPOGRAPHY was observed $(\mathrm{F}=1.896, \mathrm{p}=0.161)$, nor did we find a significant interaction effect for CONDITION x TOPOGRAPHY $(\mathrm{F}=4.247, \mathrm{p}=0.656)$. In the 500-800 ms time window, the ANOVA also showed a statistically significant main effect of CONDITION $(\mathrm{F}=8.202, \mathrm{p}=0.008)$ and no statistically significant main effect of TOPOGRAPHY $(\mathrm{F}=0.87$, $\mathrm{p}=0.425)$, nor interaction effect for CONDITION x TOPOGRAPHY $(\mathrm{F}=0.947, \mathrm{p}=0.394)$. In foreign-accented speech, the ANOVAs did not show any statistically significant main effects or interactions in any of the time windows. Table 2 shows the results from the overall TOPOGRAPHY (anterior, central, posterior) by CONDITION (expected completion, unexpected completion) ANOVAs, performed separately for native and foreign-accented speech.

Table 2: F-statistics from the grand average ANOVAs on mean amplitudes in Condition 1 (expected endings) and Condition 2 (unexpected endings) conducted for native and foreign-accented speech

\begin{tabular}{|c|c|c|c|c|c|c|c|}
\hline & \multirow[b]{2}{*}{ df } & \multicolumn{2}{|c|}{$200-500 \mathrm{~ms}$} & \multicolumn{3}{|c|}{$500-800 \mathrm{~ms}$} & \multirow[b]{2}{*}{$\mathrm{p}<0.05$} \\
\hline & & $\mathbf{F}$ & $\mathbf{P}$ & $\mathrm{p}<0.05^{3}$ & $\mathbf{F}$ & $\mathbf{p}$ & \\
\hline \multicolumn{8}{|c|}{ Native accent } \\
\hline Condition & 24 & 5.608 & 0.026 & * & 8.202 & 0.008 & $* * *$ \\
\hline Topography & 48 & 1.896 & 0.161 & & 0.870 & 0.425 & \\
\hline Condition $\mathrm{x}$ & 48 & 0.424 & 0.656 & & 0.947 & 0.394 & \\
\hline \multicolumn{8}{|l|}{ Topography } \\
\hline \multicolumn{8}{|c|}{ Foreign accent } \\
\hline Condition & 24 & 1.262 & 0.272 & & 0.831 & 0.37 & \\
\hline Topography & 48 & 2.357 & 0.105 & & 1.48 & 0.237 & \\
\hline Condition $\mathrm{x}$ & 48 & 0.812 & 0.497 & & 3.132 & 0.052 & $\dagger$ \\
\hline Topography & & & & & & & \\
\hline
\end{tabular}

\section{Discussion}

The aim of the present study was to determine whether the mechanisms responsible for categorical template matching are active during the processing of foreign-accented speech. With the aid of the ERP technique, we investigated neural reactions towards expected and unexpected template endings embedded in sentential contexts. The researchers who have previously examined the role of prediction in the processing of non-native speech tended to focus on accents which were either relatively uncommon for the listeners (Grey and van Hell 2017), or counterbalanced with respect to language common origin and accent familiarity (Goslin et al. 2012; Romero-Rivas et al. 2016). Thus, we decided to investigate the processing of an accent which would be easy to recognize in a given environment (i.e., Ukrainian accent in Polish). The obtained results demonstrate that the mechanisms of anticipation are hampered

$3+\mathrm{p}<0.1,{ }^{*} \mathrm{p}<0.05,{ }^{* * *} \mathrm{p}<0.01$ 
during the processing of non-native speech, even in the case of a well-known accent. While in the case of native-accented speech, template violations elicited a neural response, no comparable effect was observed in the case of foreign-accented speech. When interpreting the exact nature of this response (i.e., a broadly distributed N400-like effect), one has to take into account that the experimental material used in the current study did not include semantic anomalies per se but rather low cloze probability items used in place of highly expected template endings. This might explain why the scalp distribution of the observed effect is not entirely consistent with the distribution of the N400 which, although in general described as broad, is typically centro-posterior (Bridger et al. 2012; Federmeier and Kutas 1999; Voss and Federmeier 2011). What we observed in the current study in the case of native-accented speech was a globally distributed negativity, sustained over a larger time period in the anterior regions. Such characteristics correspond more adequately to the component known as the FN400 (frontal N400), indicating the involvement of familiarity memory (see, for instance, Bridger 2012; Leynes et al. 2017; Voss and Federmeier 2011 for a discussion of the potential functional differences between the N400 and FN400).

The results of the current study extend our knowledge about the mechanisms of anticipation during the processing of foreign-accented speech. The predominant assumption concerning non-native speech processing is that it increases the reliance on contextual cues: as foreign accents are not normalised at the pre-lexical level (Goslin et al. 2012), the comprehenders are forced to rely more on top-down mechanisms, i.e., to make extensive use of context and background knowledge. It is not entirely clear, however, whether the list of potential lexical candidates matching the sentential context is narrowed down or, quite contrastingly, extended under the influence of foreign-accented speech. Assuming that the increased reliance on sentential context would direct the comprehender solely at the most probable completion, the list of lexical candidates would be narrowed under the influence of a foreign accent. This would also explain the results obtained in the study conducted by Romero-Rivas et al. (2016), in which no difference was observed between completions related to the most probable sentence ending and the completions unrelated to the target word (recall (1)). However, as Romero-Rivas et al. (2016) themselves point out, the results of their experiment may also be explained in terms of the listener's diminished ability to retrieve the semantic features of the upcoming words in the adverse listening conditions (i.e., in the case of non-native speech) (Romero-Rivas et al. 2016: 25). The outcomes of the current study are more compatible with the results of an ERP experiment carried out by Goslin et al. (2012) who presented their subjects with low cloze probability words embedded in context (e.g., His wife managed to win a bag of goldfish; Goslin et al. 2012: 95). A reduced N400 amplitude was observed as a response towards such sentences in non-native speech, as compared to the native one. This result would also suggest that anticipatory mechanisms are hampered in the case of non-native speech but the increased reliance on contextual cues allows the comprehender to select a larger set of possible lexical candidates matching the context (Goslin et al. 2012: 101). In the present experiment, unexpected template endings also elicited reduced neural reaction in foreign-accented when compared with native-accented speech.

In addition, the obtained results seem to be in accord with previous findings (e.g., Hanulíková et al. 2012; Romero-Rivas et al. 2015) regarding the lack of meaning reanalysis 
during the processing of foreign-accented speech: no neural response was elicited towards template violations in the case of foreign-accented speech when compared with the nativeaccented speech (see Figure 2). As pointed out by Hanulíková et al. (2012), the P600 component is sometimes considered more sensitive towards event probability, rather than being a component that is unequivocally related to language (Hanulíková et al. 2012: 885). As second language learners typically commit grammatical errors of various kinds, the (native) comprehenders typically learn to 'ignore' the mistakes of that kind in non-native speech (Caffara and Martin 2018; Hanulíková et al. 2012). This regularity was also reflected in the outcomes of the current study. Since world knowledge suggests that non-native speakers are likely to substitute highly expected template endings with other words, template violation errors may be considered a highly probable error type which would abolish the need of reanalysis. This provides additional evidence that such indexical properties of the speaker as their foreign accent can influence neural responses associated with revision.

When it comes to the limitations of the current research, it focused specifically on the processing of common and easily recognizable type of accent. Consequently, the findings presented in this paper might be applied to the most frequent communication situations involving non-native speakers of a given language, but they cannot be related to the processing of less common types of accents, or to foreign-accented speech in general. In order to provide an extensive account concerning the mechanisms of prediction in non-native speech, more research would be needed, employing other accents, and perhaps also comprehenders of different status, i.e., not only monolinguals but also bi- or multilingual speakers, and second language learners.

To conclude, the outcomes of this research contribute to the ongoing debate on bilingualism and accentedness. Being specifically focused on the processing of well-familiar and easily recognizable accent, it complements previous studies investigating the issue of foreignaccented speech comprehension (Grey and van Hell 2017; Hanulíková et al. 2012; RomeroRivas et al. 2016). Moreover, the study provided a preliminary evidence that the mechanisms of template matching are hampered during the comprehension of non-native speech, which is consistent with recent findings regarding the lack of meaning reanalysis and shallower semantic processing of foreign as opposed to native-accented speech.

\section{References}

Adank, P., B. Evans, J. Stuart-Smith, and S. Scotti. 2009. Comprehension of familiar and unfamiliar native accents under adverse listening conditions. Journal of Experimental Psychology: Human Perception and Performance 35(2): 520-529.

Bradlow, A. R., and T. Bent. 2008. Perceptual adaptation to non-native speech. Cognition 106: 707-729.

Bridger, E. K., R. Bader, O. Kriukova, K. Unger, and A. Mecklinger. 2012. The FN400 is functionally distinct from the N400. NeuroImage 63: 1334-1342.

Caffarra, S., and C. D. Martin. 2018. Not all errors are the same: ERP sensitivity to error typicality in foreign accented speech perception. Cortex 100: 1-13.

Cristia, A., A. Seidl, C. Vaughn, R. Schmale, A. Bradlow, and C. Floccia. 2012. Linguistic processing of accented speech across the lifespan. Frontiers in Psychology 3(479): 1-15. 
Daniel O. 2019. On Human Trafficking, Schengen Visas and Drunken Workers: Czech Media Representations of Poland in Light of Three Migration Issues After 2013. In K. Marczuk (ed.), Good Neighbourhood Treaties of Poland, 145-159. Cham: Palgrave Macmillan.

Federmeier, K. D., and M. Kutas. 1999. A rose by any other name: Long-term memory structure and sentence processing. Journal of Memory and Language 41: 469-495.

Flege, J. E. 1995. Second language speech learning: Theory, findings, and problems. In W. Strange (ed.), Speech Perception and Linguistic Experience, 233-277. Baltimore: York Press.

Flege, J. E., M. J. Munro, and I. R. A. MacKay. 1995. Factors affecting strength of perceived foreign accent in a second language. Journal of the Acoustical Society of America 97(5): 3125-3134.

Floccia, C., J. Goslin, F. Girard, and G. Konopczynski. 2006. Does a regional accent perturb speech processing? Journal of Experimental Psychology: Human Perception and Performance 32: 1276-1293.

Friederici, A. D., and J. Weissenborn. 2007. Mapping sentence form onto meaning: The syntax-semantic interface. Brain Research 1146: 50-58.

Goslin, J., H. Duffy, and C. Floccia. 2012. An ERP investigation of regional and foreign accent processing. Brain and Language 122: 92-102.

Gouvea, A. C., C. Phillips, N. Kazanina, and D. Poeppel. 2009. The linguistic processes underlying the P600. Language and Cognitive Processes 25(2): 149-188.

Grey, S., and J. G. van Hell. 2017. Foreign-accented speaker identity affects neural correlates of language comprehension. Journal of Neurolinguistics 42: 93-108.

Grosjean, F. 2010. Bilingual: Life and Reality. Cambridge, MA: Harvard University Press.

Hanulíková, A., P. M. van Alphen, M. M. van Goch, and A. Weber. 2012. When one person's mistake is another's standard usage: the effect of foreign accent on syntactic processing. Journal of Cognitive Neuroscience 24: 878887.

Harley, T. A. 2013. The Psychology of Language. Hove: Taylor and Francis.

Kaan, E. 2007. Event related potentials and language processing: A brief overview. Language and Linguistic Compass 1(6): 571-591.

Kutas, M., and S. A. Hillyard. 1980. Reading senseless sentences: Brain potentials react semantic incongruity. Science 207: 203-205.

Lev-Ari, S. 2015. Comprehending non-native speakers: Theory and evidence for adjustment in manner of processing. Frontiers in Psychology 5: 1-12.

Lev-Ari, S., and B. Keysar. 2010. Why don't we believe non-native speakers. The influence of accent on credibility. Journal of Experimental Social Psychology 46(6): 1093-1096.

Leynes, P. A., H. Bruett, J. Krizan, A. Veloso. 2017. What psychological process is reflected in the FN400 eventrelated potential component. Brain and Cognition 113: 142-154.

Lindemann, S. 2002. Listening with an attitude: A model of native-speaker comprehension of non-native speakers in the United States. Language in Society 31: 419-441.

Oldfield, R. C. 1971. The assessment and analysis of handedness: The Edinburgh inventory. Neuropsychologia 9: 97-113.

Oppenheimer, D. M. 2008. The secret life of fluency. Trends in Cognitive Science 12: 237-241.

Otten, L. J., and M. D. Rugg. 2004. Interpreting event-related brain potentials. In T. C. Handy (ed.), Event-Related Potentials: A Methods Handbook, 3-16. Cambridge: MIT Press.

Pęzik, Piotr. 2012. Wyszukiwarka PELCRA dla danych NKJP. In A. Przepiórkowski, M. Bańko, R. Górski, B. Lewandowska-Tomaszczyk (eds.), Narodowy Korpus Języka Polskiego, 253-279. Warszawa: Wydawnictwo Naukowe PWN.

Polich, J. 2012. Neuropsychology of P300. In S. Luck, and E. S. Kappenman (eds.), The Oxford Handbook of EventRelated Potential Components, 159-188. Oxford: Oxford University Press.

Radomski, M., and J. Szpyra-Kozłowska. 2014. A pilot study on Poles' attitudes to foreign-accented Polish and its users. Studies in Polish Linguistics 9(2): 67-87.

Roehm, D., I. Bornkessel-Schlesewsky, F. Rösler, M., and Schlesewsky. 2007. To predict or not to predict: Influences of task and strategy on the processing of semantic relations. Journal of Cognitive Neuroscience 19(8): 1259-1274. 
Romero-Rivas, C., C. D. Martin, and A. Costa. 2015. Processing changes when listening to foreign-accented speech. Frontiers in Human Neuroscience 9: 45-59.

Romero-Rivas, C., C. D. Martin, and A. Costa. 2016. Foreign-accented speech modulated linguistic anticipatory processes. Neuropsychologia 85: 245-255.

Said, S. B. 2006. Attitudes towards Accented Speech: A Comparative Study of Native and Non-Native Speakers of American English. MA thesis, Southern Illinois, University Carbondale.

Souza, A. L., K. Byers-Heinlein, and D. Poulin-Dubois. 2013. Bilingual and monolingual children prefer nativeaccented speakers. Frontiers in Psychology 4: 953.

Vespignani, F., P. Canal, N. Molinaro, S. Fonda, and C. Cacciari. 2010. Predictive mechanisms in idiom comprehension. Journal of Cognitive Neuroscience 22(8): 1682-1700.

Voss, J. L., and K. D. Federmeier. 2011. FN400 potentials are functionally identical to N400 potentials and reflect semantic processing during recognition testing. Psychophysiology 48: 532-546.

Woodman, G. F. 2010. A Brief Introduction to the Use of Event-Related Potentials (ERPs) in Studies of Perception and Attention. Attention, Perception and Psychophysics 72(8): 1-29. 